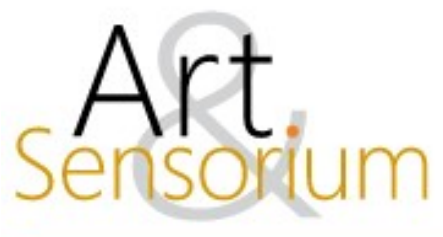

\title{
A REVISÃO INTEGRATIVA COMO MÉTODO PARA SÍNTESE DO CONHECIMENTO APLICADO A ESTUDOS SOBRE O ARTISTA ATHOS BULCÃO
}

\author{
https://doi.org/10.33871/23580437.2021.8.1.186-202
}

\author{
Emyle dos Santos Santos ${ }^{1}$ \\ Maria Herminia Olivera Hernández ${ }^{2}$
}

\begin{abstract}
Resumo: Autor de importantes obras no cenário nacional e algumas em âmbito internacional, Athos Bulcão (1918-2008) possui uma produção que se caracteriza, principalmente, por estar presente em diferentes contextos e em espaços pouco tradicionais para objetos de arte. Apontado como "artista múltiplo", seu universo de atuação suscita uma grande quantidade de publicações que incluem, depoimentos, entrevistas, inventários, pesquisas, artigos, dissertações, textos curatoriais, críticas e outros materiais bibliográficos e documentais. Contudo e apesar dessa amplitude de trabalhos, têmse a percepção de que a sua produção está sub explorada nas pesquisas acadêmicas, pois, muitas vezes, esses documentos fracionam a obra do artista, privilegiando determinadas linguagens ou conjuntos de artefatos em detrimento de outros. Nesse sentido, o artigo que se apresenta, que é adaptação de um capítulo da pesquisa de doutorado defendida em 2020, busca entender qual o estado da arte das pesquisas acadêmicas sobre Athos Bulcão, para isso optou-se pelo desenvolvimento de uma Revisão Integrativa, "[...] assim denominada por fornecer informações mais abrangentes sobre um evento particular, interconectando elementos isolados dos estudos existentes." (SAMAPAIO; MANCINI, 2007, apud FREITAS; CARVALHO; MENESCAL, 2010, p.4). Esta metodologia mostra-se promissora para a investigação de artistas e suas produções, sobretudo, quando se tem à disposição muitas informações a serem sistematizadas.
\end{abstract}

Palavras-chave: Athos Bulcão; Metodologia; Artes Visuais.

\footnotetext{
${ }^{1}$ Professora Adjunta (classe C) nível I, lotada no Departamento I: História da Arte e Pintura da Escola de Belas Artes da Universidade Federal da Bahia, em regime de trabalho DE (Dedicação Exclusiva). Ministra componentes curriculares para o curso de graduação em Decoração. Graduada em Decoração pela Universidade Federal da Bahia (UFBA) (2006 2011), Mestre (2013 - 2015) e Doutora (2016 - 2020) em Artes Visuais pelo Programa de Pós-Graduação em Artes Visuais da Escola de Belas Artes (PPGAV-EBA-UFBA). emyles@ufba.br. https://orcid.org/0000-0002-9425-9931. http://lattes.cnpq.br/8508471690448176.

${ }^{2}$ Professora Associada IV, da Universidade Federal da Bahia, Escola de Belas Artes, lidera o grupo de pesquisa: Design e Arquitetura no Universo das Artes Visuais. Atua na graduação como docente no curso de Decoração e na pós-graduação em Artes Visuais da EBA da UFBA. Concluiu doutorado em Arquitetura e Urbanismo pela Universidade Federal da Bahia (2005), mestrado em Arquitetura e Urbanismo pela Universidade Federal da Bahia (2000), especialização em Conservação e Restauração de Monumentos e Cidades Históricas - CECRE (1993) pela Universidade Federal da Bahia e em Conservação Preventiva (1999) pela Fundação Antorchas-Vitae/ Brasil em Buenos Aires, Argentina, e Graduação em Arquitectura pela Universidad de Camaguey Cuba (1986). herminia@ufba.br. https://orcid.org/0000-0003-2727-9868. http://lattes.cnpq.br/0559513435128818
} 


\title{
AN INTEGRATIVE LITERATURE REVIEW AS A MEANS OF SYNTETHIZING KNOWLEDGE ON THE WORK OF THE ARTIST ATHOS BULCÃO
}

\begin{abstract}
Author of important works in national - and sometimes international - scene, Athos Bulcão (1918-2008) has a production that is mainly characterized for being present in different contexts and spaces not very traditional for works of art. Considered as a "multiple artist", his legacy is the subject of a considerable number of documents, including testimonials, interviews, inventories, researches, articles, dissertations, curatorial papers, reviews and other bibliographic and documental materials. Nevertheless, despite the extent of his work, it seems that his production has not been the subject of much academic research. This happens because the literature on his work is fragmented, as many authors tend to restrict the scopes of their analyses to pieces that were made using specific artistic languages, or that belong to specific groups of artifacts. In this paper, an adaption of a chapter of a $\mathrm{PhD}$ thesis defended in 2020, we seek to understand what is the state of the art of the literature on Athos Bulcão. For that reason, we chose to develop an Integrative Review, "[...] named in this way in order to provide more comprehensive information on a particular event, interconnecting isolated elements from the existing studies." (SAMAPAIO; MANCINI, 2007, apud FREITAS; CARVALHO; MENESCAL, 2010, p.4). This methodology appears promising to the investigation of artists and their production, specially when there is available much information to be systemized.
\end{abstract}

Key words: Athos Bulcão; Methodology; Visual arts.

\section{LA REVISIÓN INTEGRATIVA COMO MÉTODO PARA LA SINTESIS DEL CONOCIMIENTO APLICADO A ESTUDIOS SOBRE EL ARTISTA ATHOS BULÇÃO}

Resumen: Autor de importantes obras en el escenario nacional y algunas en el ámbito internacional, Athos Bulção (1918-2008) tiene una producción que se caracteriza, principalmente, por estar presente en diferentes contextos y en espacios poco tradicionales para objetos de arte. Apuntado como "artista múltiplo", su universo de actuación promueve una gran cantidad de publicaciones que incluyen, declaraciones, entrevistas, inventarios, investigaciones, artículos, disertaciones, textos curatoriales, críticas y muchos otros materiales bibliográficos y documentales. Todavía y mismo con esa amplitud de trabajos, se percibe que su producción esta subexplorada en las investigaciones académicas, pues, muchas veces, esos documentos fraccionan la obra del artista, privilegiando determinadas lenguajes o conjuntos de artefactos en desventaja de otros. En este sentido, el artículo que se presenta, adaptado de un capítulo de la investigación de doctorado defendida em 2020, busca entender cual es el estado del arte de las investigaciones académicas sobre Athos Bulção, para eso fue decidida la realización de una Revisión Integrativa, "[...] denominada así por ofrecer informaciones mas amplias sobre un evento particular, interconectando elementos separados de los estudios existentes." (SAMAPAIO; MANCINI, 2007, apud FREITAS; CARVALHO; MENESCAL, 2010, p.4). Esta metodología se demuestra válida para la investigación de artistas y sus producciones, sobre todo, cuando se tiene a disposición muchas informaciones para ser sistematizadas.

Palabras clave: Athos Bulcão; Metodología; Artes Visuales. 


\section{Um artista múltiplo}

Autor de importantes obras no cenário nacional e algumas em âmbito internacional, Athos Bulcão (1918-2008) possui uma produção que se caracteriza, principalmente, por estar presente em diferentes contextos e em espaços pouco tradicionais para objetos de arte. Sua atuação atravessou mais de 50 anos (de 1939 à $2000^{3}$ ), integrando uma relevante geração de artistas nacionais ${ }^{4}$ que contribuíram de maneira fundamental para a consolidação das artes visuais no Brasil, participando da construção de Brasília.

Ao designar Athos como um "artista múltiplo", deseja-se evidenciar dois aspectos principais em sua produção: primeiro, a pluralidade de suas experimentações, tanto em técnicas, como em procedimentos; e segundo, as suas diferentes atuações profissionais, bem como a maneira como tais saberes contribuíram para o seu processo formativo ${ }^{5}$. Sua produção abrangeu diversas linguagens, dentre elas: as ilustrações de livro e jornal, diagramações de capas revistas, catálogos e discos, decorações perenes e efêmeras, croquis de moda, cenografia, trajes e figurinos para peças teatrais, painéis de azulejo, divisórias, painéis vitrais, mosaicos, pinturas de cavalete e murais, desenhos, serigrafias, escultura e outras obras relacionadas à arquitetura, como murais, relevos, painéis de azulejos, mobiliário fixo, portas, vitrais, esquadrias, divisórias, diagramação de piso, forros e tetos.

O trânsito profissional de Athos em diversos ofícios inclui: decorador de interiores, criador de decoração efêmera, designer gráfico, ilustrador, cenógrafo e professor universitário. Esse afluxo pode ser entendido como tentativas de inovação no fazer artístico, dessa forma, a inserção em diversos campos do saber colaborou para o enriquecimento de suas possibilidades de expressão, de seu processo criativo e seu modo de conceber arte, sobretudo, através das trocas entre os pares, absorvendo diferentes valores para a criação de uma linguagem plástica única.

Importa mencionar que o contexto histórico de formação do artista se deu nas décadas de 1940 e 1950, quando, no Brasil, aconteciam movimentos como Modernismo, Concretismo, Neoconcretismo, Abstracionismo, Cubismo, entre outros. Mas, mesmo sendo contemporâneo a esses movimentos, Athos conseguiu desenvolver seu próprio caminho, sem se vincular declaradamente a nenhum deles, lidando com estas vertentes sem se deixar levar por modismos.

Todavia, é possível perceber em sua produção a influência das várias vertentes abstratas do final da década de 1940 e início da década de 1950 no Brasil, e também a relação com a produção artística dos seus pares, com quem travou relação direta, tendo frequentado suas casas e ateliês, aprendendo e trocando experiências. Assim, mesmo sem se declarar participante ou seguidor de algum movimento de vanguarda, entende-se que os acontecimentos em seu contexto próximo acabaram influenciando seu processo formativo. Associa-se esse afluxo ao conceito de "troc" de Baxandall (2006), que diz

\footnotetext{
${ }^{3}$ Período aproximado de produção artística de Athos Bulcão, tendo em vista que em 1989 ele foi diagnosticado com Mal de Parkinson, mas, apesar disso, continuou produzindo intensamente. Apenas nos seus últimos anos de vida, interrompeu sua profícua obra pelo agravamento da doença.

${ }^{4}$ Dentre os amigos e parceiros profissionais de Athos Bulcão, se destacam Jorge Amado (1912-2001), Roberto Burle Marx (1909-1994), Vinícius de Moraes (1913-1980), Fernando Sabino (1923-2004), Manuel Bandeira (1886-1968), Candido Portinari (1903-1962), Oscar Niemeyer (1907-2012), Carlos Scliar (1920-2001), Enrico Bianco (1918-2013), José Pancetti (1902-1958), Milton Dacosta (1915-1988), Joaquim Tenreiro (1906-1992), Lucio Cardoso (1912-1968), Murilo Mendes (1901-1975), Maria Helena Vieira da Silva (1908-1992) e Arpad Szenes (1897-1985) (FUNDATHOS, 2014)

${ }^{5}$ A concepção de processo formativo ou formatividade em artes deriva de Pareyson (1993), que defende que o próprio fazer do artista - com suas tentativas, erros e acertos - inventa o modo de fazer, não se limitando a realizar algo já idealizado ou com regras pré-estabelecidas. Nesse processo, invenção e produção caminham lado a lado. Partindo desse pressuposto, formar significa fazer, e fazer de tal maneira que, ao fazer, se invente o "modo de fazer". O autor ressalta a importância das tentativas no processo formativo e define o ato de formar como um tentar, já que consiste na capacidade de figurar múltiplas possibilidades e, ao mesmo tempo, encontrar, entre elas, a melhor. Essa noção é compatível com Athos Bulcão, que, a partir da multiplicidade de fazeres, inventou seu modo particular de criar.
} 
respeito às permutas entre artistas, suas comunicações, colaborações, seus contextos culturais e ao modo como essas variáveis interferem no contexto geral de todos os participantes.

Apesar dessa amplitude, têm-se a percepção que a sua produção está sub explorada nas pesquisas acadêmicas, pois, muitas vezes, esses documentos fracionam a produção do artista, privilegiando determinada obra ou conjunto. Assim, têm-se a impressão que a produção artística de Athos Bulcão é, de certo modo, negligenciada e/ou simplificada, principalmente quando é tratada apenas sob a categoria de revestimento ou complemento à arquitetura, ou como uma espécie de ornamentação; e não como uma expressão com valor artístico, resultante de um processo criativo complexo e cheio de significações. Além disso, a frequente designação de integração da arte com a arquitetura na produção de Athos Bulcão, em geral, se limita a apontar a perspectiva arquitetônica sobre o fenômeno, não contemplando movimentos artísticos e suas influências. Também raramente aborda a postura dos artistas para a integração ou mesmo discute a relação de colaboração, não esclarecendo o papel de cada profissional e suas metodologias.

As abordagens também se mostraram diversas, indo da história à arquitetura, passando pelo estudo do patrimônio, turismo e educação, de acordo com o viés de interesse do pesquisador que empreendeu o estudo. Partindo desse entendimento, busca-se entender qual o estado da arte das pesquisas acadêmicas sobre Athos Bulcão, portanto, se fez necessário um amplo levantamento para conformar os dados sobre um artista tão plural.

Em busca de validar tal percepção optou-se pelo desenvolvimento de uma Revisão Integrativa, “[...] assim denominada por fornecer informações mais abrangentes sobre um evento particular, interconectando elementos isolados dos estudos existentes." (SAMAPAIO; MANCINI, 2007, apud FREITAS; CARVALHO; MENESCAL, 2010, p.4). A opção por essa metodologia, frente as outras modalidades de revisão bibliográfica e documental, se baseou na amplitude da abrangência da Revisão Integrativa, permitindo inclusão de estudos e outros documentos, além de incorporar um vasto leque de propósitos, como, a definição de conceitos, revisão de teorias e evidências, e análise de problemas metodológicos de um tópico particular, como é descrito por Whittemore e Knafl (2005) citado por Souza, Silva e Carvalho (2010). Para os referidos autores, essa ampla amostra deve gerar um panorama consistente e compreensível de conceitos complexos.

Ainda em relação às vantagens do uso da Revisão Integrativa para sistematizar referências, Freitas, Carvalho e Menescal (2010) destacam que este é um método científico que se mantém receptivo à introdução de novos estudos ou mesmo no decorrer da coleta de dados, o que auxilia na detecção de lacunas em áreas do conhecimento e incentiva o desenvolvimento de novas pesquisas, proporcionando economia de recursos, uma vez que possibilita a síntese do conhecimento já produzido. Ciente da grande quantidade de publicações sobre Athos Bulcão e alguns aspectos de sua obra, e sabendo de sua variedade (incluindo depoimentos, entrevistas, inventários, pesquisas, artigos, dissertações, textos curatoriais, críticas e outros materiais bibliográficos e documentais), essa metodologia encontra grande aderência com a proposta de estudo pretendida.

A elaboração da revisão permitiu a aproximação com o artista, suas diversas linguagens, métodos e processos de criação, contribuindo para uma visão do todo, sendo fundamental para a compreensão mais ampla dos fenômenos que conformaram sua produção. Por fim, mostrou-se uma metodologia promissora para a investigação de artistas e suas produções, sobretudo, quando se tem à disposição um grande número de informações a serem sistematizadas.

\section{Revisão Integrativa}

Os autores que embasaram a elaboração deste modelo de revisão foram Souza, Silva e Carvalho (2010) e juntamente com Freitas, Carvalho e Menescal (2010), os quais, cada qual a seu modo, se ocuparam da descrição do método, suas etapas e demonstraram possibilidades de aplicação, bem 
como suas investigações serviram de base para o desenvolvimento das fases elaboradas no presente estudo.

Souza, Silva e Carvalho (2010) detalham seis etapas ou fases para elaboração de Revisões Bibliográficas Integrativas. São elas: elaboração da pergunta norteadora; busca ou amostragem na literatura; coleta de dados; análise crítica dos estudos incluídos; discussão dos resultados; e apresentação da Revisão Integrativa. Sobre a $1^{\text {a }}$ fase, as autoras destacam a importância da definição da pergunta norteadora, pois esta decisão vai determinar quais serão os critérios de inclusão dos estudos e que informações serão coletadas. $\mathrm{Na} 2^{\mathrm{a}}$ fase, semelhantemente, é proposta uma busca ampla e diversificada, a fim de contemplar diferentes bases de dados e variedades de tipos de documentos. Devem ser expostos claramente os critérios de inclusão e exclusão dos estudos, caso não sejam interessantes para a pesquisa, sobretudo, quando é encontrado um grande volume de resultados. Essa etapa está diretamente ligada à primeira e deve responder plenamente à pergunta elaborada na busca. $\mathrm{Na} 3^{\mathrm{a}}$ fase, as autoras destacam a importância de escolher um instrumento que garanta a observação de todos os dados relevantes para a pesquisa, sua transcrição correta e seu registro. A $4^{\mathrm{a}}$ fase é caracterizada pela classificação e análise dos trabalhos. Para tanto, sugere-se a definição de pontos que serão analisados, servindo para selecionar os estudos que melhor descrevem o fenômeno pesquisado. A $5^{\mathrm{a}}$ fase consiste na síntese e discussão dos dados analisados. Finalmente, a $6^{\mathrm{a}}$ fase propõe a apresentação da análise integrativa, permitindo que os leitores avaliem criticamente (GALVÃO; SAWADA; TREVIZAN, 2004; GANONG, 1987; URSI, 2005; STETLER et al, 1998; SILVEIRA, 2005, apud SOUZA; SILVA; CARVALHO, 2010).

Com base nas referidas instruções, na $1^{a}$ fase, foi elaborada a seguinte questão norteadora: quais os acontecimentos principais da vida que repercutem na obra de Athos Bulcão?. A partir dela, buscouse localizar estudos e documentos que contivessem tais informações, visando uma aproximação geral com os dois temas. A princípio, foram incluídos todos os trabalhos encontrados que contemplavam, de algum modo, a questão definida. A $2^{\text {a }}$ fase se deu a partir do estabelecimento do critério de escolha e busca das bases de dados. As bases selecionadas foram: a Fundação Athos Bulcão (Fundathos) e o Repositório Institucional da Universidade de Brasília (UNB).

No site da Fundathos, todos os documentos presentes na seção publicações foram selecionados e catalogados para análise posterior. Optou-se por verificar todos os itens ali contidos, uma vez que se trata de uma seleção realizada pela fundação que se dedica a preservar a memória do artista. Desse modo, foram consultados os vinte e oito documentos que incluem: entrevistas, artigos de periódico, capítulos de livro, textos curatoriais e afins. Já no Repositório da UNB, as buscas se iniciaram a partir da palavra-chave "Athos Bulcão" e resultaram na identificação de cinco trabalhos. Esse levantamento ocorreu entre 2017 e 2018.

As referências encontradas durante a pesquisa conduziram à descoberta de outros estudos em plataformas digitais, sendo levantados documentos em diferentes níveis, como artigos, monografias, inventários, entrevistas, dissertações, entre outros. Foram pesquisados também catálogos de exposições, físicos e digitais, que esclareceram o parecer de curadores e críticos de arte a respeito das obras de Athos. Optou-se por manter indefinido o limite temporal para o material levantado, por compreender que todos os documentos dessa natureza poderiam conter informações relevantes para o cumprimento da pesquisa.

$\mathrm{Na} 3^{\mathrm{a}}$ fase, os trabalhos encontrados foram analisados preliminarmente e agrupados em um quadro, baseado no modelo de quadro sinóptico elaborado por Freitas, Carvalho e Menescal (2010), porém, acrescentando mais espaços para a inserção de dados e suprimindo outros considerados desnecessários para este estudo. Os dados escolhidos para compor o quadro sinóptico foram: título, nome do(s) autor(es), juntamente com o ano da publicação, as palavras-chave (quando existentes), os principais temas tratados, a abordagem e o local de acesso ao documento (endereço online para recuperação do arquivo, no caso dos trabalhos disponíveis em meio digital). O primeiro quadro sinóptico elaborado possui um total de 64 trabalhos, cuja organização se deu a partir da leitura dos 
resumos e sumários. Em alguns casos, foi necessária a leitura de capítulos e subcapítulos cujos temas tangenciavam os assuntos de interesse da tese ${ }^{6}$. A sistematização dos dados coletados, em formato de quadro, possibilitou uma visão ampliada das abordagens existentes sobre o tema geral, no caso, Athos Bulcão e sua obra, além de auxiliar na seleção dos documentos relevantes para a pesquisa, direcionando sua leitura completa.

Para o desenvolvimento da $4^{\text {a }}$ fase, Souza, Silva e Carvalho (2010) recomendam que sejam definidos itens específicos para a seleção final dos trabalhos, os quais serão analisados de maneira crítica. Assim, para a elaboração do segundo quadro sinóptico (Quadro 1), contendo apenas os documentos mais significativos, foi realizada uma leitura mais aprofundada dos textos e documentos levantados inicialmente, buscando aqueles que contivessem contribuições para o desenvolvimento deste artigo. Paralelamente, foram adotados como critério de escolha: (1) autoria dos estudos ou documentos, optando por trabalhos escritos por especialistas, mestres e doutores e críticos de arte; (2) grau de aprofundamento e validação das pesquisas por seus pares, nesse caso, optou-se por artigos de periódicos e artigos apresentados em eventos, bem como dissertações ou teses defendidas em instituições de ensino reconhecidas; (3) procedência da informação e referencial teórico, assim, buscou-se pesquisas desenvolvidas a partir de fontes primárias de informação e/ou entrevistas, bem como referencial teórico extenso/significativo, ou seja, mais de seis referências consistentes, pautados em pesquisas acadêmicas e documentos históricos.

Nas últimas fases da Revisão Integrativa, a $5^{\mathrm{a}}$ e a $6^{\mathrm{a}}$ fases, são discutidos os resultados preliminares do estudo, as impressões acerca do levantamento, os trabalhos selecionados e as conclusões. Tais discussões e impressões são apresentadas após o quadro sinóptico ${ }^{7}$ neste artigo. Como já mencionado foram elaborados dois quadros sinópticos, um preliminar com 64 trabalhos, e um definitivo, com 28 trabalhos. Por uma questão de espaço, será apresentado apenas o quadro definitivo ${ }^{8}$. Os trabalhos consultados foram divididos em subcategorias, são elas: inventário (1); entrevistas (3); texto curatorial e texto de exposição (4); capítulo de livro (2); artigo de periódico (6); trabalhos apresentados em eventos ou contidos em anais de eventos (5); e dissertação de mestrado (7). Tais categorias aparecem identificadas por diversas nuances de cores.

Quadro 1 - Quadro sinóptico dos trabalhos selecionados para Revisão Integrativa

\begin{tabular}{|c|c|c|c|}
\hline Título do Trabalho & Modalidade & Autor/Data & Temas \\
\hline $\begin{array}{l}\text { Inventário da obra de } \\
\text { Athos Bulcão em } \\
\text { Brasília. }\end{array}$ & Inventário & $\begin{array}{lr}\text { IPHAN-DF (2018) } \\
\text { Sandra } & \text { Bernardes } \\
\text { Ribeiro; } & \text { Thiago } \\
\text { Pereira } & \text { Perpétuo } \\
\text { (coord.) } & \end{array}$ & $\begin{array}{l}\text { Obras de Athos Bulcão situadas em Brasília; } \\
\text { descrição formal; dados técnicos; análises } \\
\text { estilísticas e iconográficas; relação com } \\
\text { produção artística contemporânea. }\end{array}$ \\
\hline $\begin{array}{l}\text { Depoimento - } \\
\text { Programa de História } \\
\text { Oral. Athos Bulcão. } \\
\text { Arquivo Público do } \\
\text { Distrito Federal. }\end{array}$ & $\begin{array}{l}\text { Entrevista/ } \\
\text { Depoimento a } \\
\text { Georgete } \\
\text { Medleg; } \\
\text { Sebastião } \\
\text { Afonso Moreira } \\
\text { Fonseca. }\end{array}$ & $\begin{array}{l}\text { Athos } \\
(1988)\end{array}$ & $\begin{array}{l}\text { Dados biográficos; processo formativo; atuações } \\
\text { profissionais; transferência para Brasília; } \\
\text { parceria com artistas e arquitetos; modus } \\
\text { operandi; o trabalho na Novacap. }\end{array}$ \\
\hline Athos Bulcão: & $\begin{array}{lr}\text { João } & \text { Filgueiras } \\
\text { Lima } & \text { em } \\
\text { entrevista }\end{array}$ & $\begin{array}{l}\text { Cláudia Estrela } \\
\text { Porto (2009) }\end{array}$ & $\begin{array}{l}\text { Aspectos da biografia de Athos; Relatos de Lelé } \\
\text { sobre a colaboração profissional com Athos; }\end{array}$ \\
\hline
\end{tabular}

\footnotetext{
${ }^{6}$ Santos (2020).

${ }^{7}$ Neste quadro sinóptico, os itens "abordagem", "palavras-chave" e "endereço de hospedagem do trabalho consultado" foram suprimidos para otimização do espaço.

${ }^{8}$ Ver tabelas nos apêndices de Santos (2020, p.255 a 283).
} 


\begin{tabular}{|c|c|c|c|}
\hline $\begin{array}{l}\text { A linha tênue entre } \\
\text { arte e arquitetura }\end{array}$ & $\begin{array}{l}\text { concedida a } \\
\text { Cláudia Estrela } \\
\text { Porto. }\end{array}$ & & $\begin{array}{l}\text { obras realizadas em parceria; modus operandi; a } \\
\text { produção para a Rede Sarah. }\end{array}$ \\
\hline $\begin{array}{l}\text { Habitante do silêncio } \\
\text { em Brasília }\end{array}$ & $\begin{array}{l}\text { Athos Bulcão } \\
\text { em entrevista } \\
\text { concedida a } \\
\text { Carmem } \\
\text { Moretzsohn. }\end{array}$ & $\begin{array}{l}\text { Carmem } \\
\text { Moretzsohn (2009) }\end{array}$ & $\begin{array}{l}\text { Aspectos da biografia de Athos; trajetória } \\
\text { artística e processo formativo; referências } \\
\text { artísticas; modus operandi; vivências pessoais. }\end{array}$ \\
\hline $\begin{array}{l}\text { Exposição Pinturas, } \\
\text { Máscaras e Objetos }\end{array}$ & $\begin{array}{l}\text { Apresentação de } \\
\text { Exposição } \\
\text { individual }\end{array}$ & $\begin{array}{l}\text { Paulo Herkenhoff } \\
\text { (1987) }\end{array}$ & $\begin{array}{l}\text { Contextualização do cenário artístico na década } \\
\text { de 1950; a fotografia e a fotomontagem na obra } \\
\text { de Athos; o azulejo e a pintura de Athos; a } \\
\text { relação arte-arquitetura na produção de Athos; } \\
\text { modus operandi. }\end{array}$ \\
\hline Athos Bulcão & $\begin{array}{lr}\text { Texto } & \text { em } \\
\text { catálogo } & \text { de } \\
\text { exposição. } & \end{array}$ & $\begin{array}{l}\text { João } \quad \text { Filgueiras } \\
\text { Lima (2013) }\end{array}$ & $\begin{array}{l}\text { Aspectos da biografia de Athos; processo } \\
\text { formativo; parcerias com arquitetos (Lelé e } \\
\text { Niemeyer); influências artísticas de Athos; a } \\
\text { integração da arte com a arquitetura; a } \\
\text { contribuição de Athos para a produção da Rede } \\
\text { Sarah. }\end{array}$ \\
\hline $\begin{array}{ll}\text { Athos Bulcão } & - \\
\text { Tradição } & \text { e } \\
\text { modernidade } & \end{array}$ & $\begin{array}{lr}\text { Catálogo } & \text { de } \\
\text { Exposição } & \text { na } \\
\text { Caixa } & \text { Cultural } \\
\text { de } & \text { Salvador, } \\
2017 & \end{array}$ & $\begin{array}{l}\text { Marcus de Lontra } \\
\text { Costa (2017) }\end{array}$ & $\begin{array}{l}\text { Aspectos da biografia de Athos; processo } \\
\text { formativo; parcerias com arquitetos e artistas; } \\
\text { contextualização do cenário artístico na década } \\
\text { de 1950; azulejaria na produção de Athos; } \\
\text { relação da sua produção artística com a } \\
\text { arquitetura. }\end{array}$ \\
\hline $\begin{array}{l}\text { O imaginário segundo } \\
\text { Athos Bulcão }\end{array}$ & $\begin{array}{lr}\text { Texto } & \text { em } \\
\text { catálogo } & \text { de } \\
\text { exposição: } & 100 \\
\text { anos de } & \text { Athos } \\
\text { Bulcão } & \end{array}$ & Panitz (2018) & $\begin{array}{l}\text { Aspectos da biografia de Athos; processo } \\
\text { formativo; parcerias; formas e cores na obra de } \\
\text { Athos; modus operandi; aproximações entre } \\
\text { obras de Athos e seus discípulos. }\end{array}$ \\
\hline Sentido e Urbanidade & Capítulo de livro & $\begin{array}{l}\text { Paulo Sergio Duarte } \\
\text { (2008) }\end{array}$ & $\begin{array}{l}\text { Urbanidade na obra de Athos; Arte pública; a } \\
\text { integração da arte com a arquitetura; parceria de } \\
\text { Athos com Lelé na Rede Sarah. }\end{array}$ \\
\hline Athos Bulcão & Capítulo de livro & $\begin{array}{l}\text { André Correa do } \\
\text { Lago (2009) }\end{array}$ & $\begin{array}{l}\text { A obra de Athos voltada para a arquitetura; a } \\
\text { integração da arte com a arquitetura; movimento } \\
\text { moderno brasileiro; azulejaria em Athos; } \\
\text { parcerias com arquitetos. }\end{array}$ \\
\hline $\begin{array}{l}\text { Sinfonias } \\
\text { Modernidade }\end{array}$ & $\begin{array}{l}\text { Artigo } \\
\text { periódico }\end{array}$ & $\begin{array}{l}\text { Marcus de Lontra } \\
\text { Costa (1987) }\end{array}$ & $\begin{array}{l}\text { Modernismo; obra de Athos; contribuição em } \\
\text { Brasília; parcerias com arquitetos; influências } \\
\text { artísticas de Athos; aproximações com artistas } \\
\text { contemporâneos; a integração da arte com a } \\
\text { arquitetura; a cor e as linguagens na obra de } \\
\text { Athos. }\end{array}$ \\
\hline $\begin{array}{l}\text { Sintonia de Arte e } \\
\text { Arquitetura }\end{array}$ & $\begin{array}{l}\text { Artigo } \\
\text { periódico }\end{array}$ & $\begin{array}{l}\text { Claudio } \\
\text { (1997) }\end{array}$ & $\begin{array}{l}\text { Aspectos da biografia de Athos; processo } \\
\text { formativo; contextualização do cenário artístico } \\
\text { na década de 1940; atuação profissional e } \\
\text { parcerias com arquitetos; modus operandi; } \\
\text { integração da arte com a arquitetura; parceria de } \\
\text { Athos com Lelé na Rede Sarah. }\end{array}$ \\
\hline $\begin{array}{l}\text { Os azulejos de } \\
\text { Portinari e Athos } \\
\text { Bulcão como }\end{array}$ & $\begin{array}{l}\text { Artigo de } \\
\text { periódico }\end{array}$ & $\begin{array}{l}\text { Sandra } \\
\text { Mattei } \\
(2012)\end{array}$ & $\begin{array}{l}\text { Azulejo; azulejaria na arquitetura do Brasil; } \\
\text { integração arte/arquitetura; Modernismo no } \\
\text { Brasil; aproximações entre Athos Bulcão e } \\
\text { Portinari; aspectos da biografia de Athos e }\end{array}$ \\
\hline
\end{tabular}

${ }^{9}$ Texto publicado originalmente no Jornal do Arquiteto, ano I, n. ${ }^{\circ}$ 5, novembro de 1996.

R. Inter. Interdisc. Art\&Sensorium, Curitiba, v.8, n.1, p. 186 - 202 Jan.- Jun. 2021 


\begin{tabular}{|c|c|c|c|}
\hline $\begin{array}{l}\text { elementos } \\
\text { ornamentais da } \\
\text { Arquitetura } \\
\text { modernista no Brasil }\end{array}$ & & & $\begin{array}{l}\text { Portinari; azulejaria de Athos e Portinari; } \\
\text { estratégias de preservação. }\end{array}$ \\
\hline $\begin{array}{l}\text { A itinerância dos } \\
\text { artistas: a construção } \\
\text { do campo das artes } \\
\text { visuais em Brasília } \\
(1958-1967)\end{array}$ & $\begin{array}{ll}\text { Artigo } & \mathrm{de} \\
\text { periódico } & \end{array}$ & $\begin{array}{l}\text { Angélica Madeira } \\
(2002)\end{array}$ & $\begin{array}{l}\text { A criação de Brasília; contextualização do } \\
\text { cenário artístico na década de 1950; o papel de } \\
\text { arte na construção de Brasília e seus valores } \\
\text { simbólicos; movimentos de vanguarda no Brasil; } \\
\text { aproximações entre Athos Bulcão e Rubem } \\
\text { Valentim; aspectos da biografia de Athos Bulcão } \\
\text { e Rubem Valentim. }\end{array}$ \\
\hline $\begin{array}{l}\text { Síntese das Artes na } \\
\text { Arquitetura de Oscar } \\
\text { Niemeyer }\end{array}$ & $\begin{array}{ll}\text { Artigo } & \text { de } \\
\text { periódico } & \end{array}$ & $\begin{array}{l}\text { Magda } \\
\text { (2003) }\end{array}$ & $\begin{array}{l}\text { Síntese das artes; a contribuição de Athos na } \\
\text { arquitetura; a integração e síntese das artes na } \\
\text { arquitetura (subordinação, colaboração, } \\
\text { integração da arte a arquitetura); arquitetura } \\
\text { moderna; movimentos de vanguarda no Brasil e } \\
\text { no mundo; integração das artes na arquitetura. }\end{array}$ \\
\hline $\begin{array}{l}\text { Integração das Artes: } \\
\text { Os azulejos de Athos } \\
\text { Bulcão }\end{array}$ & $\begin{array}{ll}\text { Artigo } & \mathrm{de} \\
\text { periódico } & \end{array}$ & $\begin{array}{l}\text { Bárbara Duarte } \\
(2008)\end{array}$ & $\begin{array}{l}\text { Azulejaria; a integração das artes na arquitetura; } \\
\text { Aspectos da biografia de Athos; processo } \\
\text { formativo; cor e formas no trabalho de Athos; } \\
\text { movimentos de vanguarda no Brasil e no mundo. }\end{array}$ \\
\hline $\begin{array}{l}\text { Quando Arte e } \\
\text { Arquitetura se } \\
\text { mesclam: A obra de } \\
\text { Athos Bulcão e Lelé }\end{array}$ & $\begin{array}{l}\text { Trabalho } \\
\text { apresentado em } \\
\text { Evento/Anais de } \\
\text { Evento }\end{array}$ & $\begin{array}{l}\text { Cláudia Estrela } \\
\text { Porto }(2009 a)\end{array}$ & $\begin{array}{l}\text { Aspectos da biografia de Athos; processo } \\
\text { formativo; relação arte-arquitetura; movimentos } \\
\text { de vanguarda no Brasil e no mundo; a integração } \\
\text { das artes na arquitetura; parceria de Athos com } \\
\text { arquitetos; parceria de Athos com Lelé; A } \\
\text { contribuição de Athos para a produção de Lelé; } \\
\text { obras de Lelé baseadas em Athos. }\end{array}$ \\
\hline $\begin{array}{l}\text { A obra de Athos } \\
\text { Bulcão, ponto alto da } \\
\text { vertente construtiva }\end{array}$ & $\begin{array}{l}\text { Trabalho } \\
\text { apresentado em } \\
\text { Evento/Anais de } \\
\text { Evento. }\end{array}$ & $\begin{array}{l}\text { Agnaldo } \quad \text { Farias } \\
(2009)\end{array}$ & $\begin{array}{l}\text { Aspectos da biografia de Athos; modus } \\
\text { operandi; história da arte e arquitetura; } \\
\text { apagamento e preservação da memória de Athos. }\end{array}$ \\
\hline $\begin{array}{l}\text { A diluição do Plano } \\
\text { Bidimensional no } \\
\text { Espaço: análises e } \\
\text { relações entre quatro } \\
\text { obras seminais de } \\
\text { integração } \\
\text { arquitetônica } \\
\text { Athos Bulcão }\end{array}$ & $\begin{array}{l}\text { Trabalho } \\
\text { apresentado em } \\
\text { Evento/Anais de } \\
\text { Evento }\end{array}$ & $\begin{array}{l}\text { Leandro } \\
\text { (2012) }\end{array}$ & $\begin{array}{l}\text { A síntese nas artes modernas; o legado de Athos } \\
\text { Bulcão; a integração das artes na arquitetura; } \\
\text { azulejaria; aspectos da biografia de Athos; } \\
\text { processo formativo; parceria de Athos com Lelé. }\end{array}$ \\
\hline $\begin{array}{l}\text { Os painéis de Athos } \\
\text { Bulcão na arquitetura } \\
\text { de Brasília: Uma } \\
\text { tradução Candanga do } \\
\text { Projeto Construtivo } \\
\text { Brasileiro? }\end{array}$ & $\begin{array}{l}\text { Trabalho } \\
\text { apresentado em } \\
\text { Evento/Anais de } \\
\text { Evento }\end{array}$ & $\begin{array}{l}\text { Fabiana Carvalho } \\
\text { de Oliveira (2012) }\end{array}$ & $\begin{array}{l}\text { Ideal construtivista; a integração das artes na } \\
\text { arquitetura; movimentos de vanguarda no Brasil } \\
\text { e no mundo; ideário modernista internacional em } \\
\text { Brasília; movimentos artísticos que } \\
\text { influenciaram na obra de Athos; }\end{array}$ \\
\hline $\begin{array}{l}\text { Entre o concreto e } \\
\text { o abstrato: As obras } \\
\text { de Armando de } \\
\text { Holanda Cavalcanti } \\
\text { com Athos Bulcão }\end{array}$ & $\begin{array}{l}\text { Trabalho } \\
\text { apresentado em } \\
\text { Evento/Anais de } \\
\text { Evento }\end{array}$ & $\begin{array}{l}\text { Clarissa Carvalho e } \\
\text { Silva; Adriana } \\
\text { Freire de } \\
\text { Oliveira; Guilah } \\
\text { Naslavsky (2016) }\end{array}$ & $\begin{array}{l}\text { Arte-arquitetura enquanto manifestação cultural; } \\
\text { Modernismo no Brasil; Abstracionismo } \\
\text { Geométrico; síntese das artes; integração das } \\
\text { artes; autonomia das artes; parceria entre Athos e } \\
\text { Armando H. Cavalcanti. }\end{array}$ \\
\hline $\begin{array}{l}\text { Azulejo na arquitetura } \\
\text { brasileira: os painéis } \\
\text { de Athos Bulcão }\end{array}$ & $\begin{array}{l}\text { Dissertação de } \\
\text { Mestrado. }\end{array}$ & $\begin{array}{l}\text { Ingrid } \quad \text { Moura } \\
\text { Wanderley (2006) }\end{array}$ & $\begin{array}{l}\text { História do azulejo na arquitetura; produção e } \\
\text { técnica de azulejaria; arquitetura moderna } \\
\text { brasileira; contexto histórico e político da } \\
\text { produção artística do azulejo no Modernismo no }\end{array}$ \\
\hline
\end{tabular}

R. Inter. Interdisc. Art\&Sensorium, Curitiba, v.8, n.1, p. 186 - 202 Jan.- Jun. 2021 


\begin{tabular}{|c|c|c|c|}
\hline & & & $\begin{array}{l}\text { Brasil; a síntese das artes; Athos Bulcão e a } \\
\text { azulejaria; a obra pública e o anonimato. }\end{array}$ \\
\hline $\begin{array}{l}\text { Ventania, de Athos } \\
\text { Bulcão: ruptura e } \\
\text { integração }\end{array}$ & $\begin{array}{l}\text { Dissertação de } \\
\text { Mestrado }\end{array}$ & $\begin{array}{l}\text { Bárbara Pinto } \\
\text { Duarte (2009) }\end{array}$ & $\begin{array}{l}\text { Aspectos da biografia de Athos; processo } \\
\text { formativo; modus operandi; contextualização } \\
\text { sobre Arte Moderna do século XX (crítica e } \\
\text { interpretação); classificação das obras de Athos } \\
\text { (arte mural ou decoração); aproximações da } \\
\text { produção de Athos com design gráfico; aspectos } \\
\text { técnicos da azulejaria; história da azulejaria no } \\
\text { Brasil e na arquitetura moderna. }\end{array}$ \\
\hline $\begin{array}{lr}\text { Estratégias } & \text { para a } \\
\text { preservação } & \text { do } \\
\text { patrimônio } & \text { cultural } \\
\text { moderno: } & \text { Athos } \\
\text { Bulcão em } & \text { Brasília } \\
(1957-2007) & \end{array}$ & $\begin{array}{ll}\text { Dissertação } & \mathrm{de} \\
\text { Mestrado } & \\
\text { profissional } & \end{array}$ & $\begin{array}{l}\text { Fabiana Carvalho } \\
\text { de Oliveira (2012) }\end{array}$ & $\begin{array}{l}\text { Aspectos da biografia de Athos; processo } \\
\text { formativo; modus operandi; contextualização } \\
\text { sobre Modernismo no Brasil; patrimônio e } \\
\text { estratégias de preservação; artes em Brasília; } \\
\text { tipologia e agrupamento das obras; materiais e } \\
\text { técnicas. }\end{array}$ \\
\hline $\begin{array}{l}\text { Ressignificações das } \\
\text { obras de Athos } \\
\text { Bulcão nos espaços de } \\
\text { Brasília: } \\
\text { Entre a obra de arte e } \\
\text { o ornamento }\end{array}$ & $\begin{array}{l}\text { Dissertação de } \\
\text { Mestrado }\end{array}$ & $\begin{array}{l}\text { Fabiana Carvalho } \\
\text { de Oliveira (2013) }\end{array}$ & $\begin{array}{l}\text { A integração das artes na arquitetura; soluções } \\
\text { formais na integração da obra de arte em Braília; } \\
\text { arte inserida a posteriori; contextualização do } \\
\text { cenário artístico na década de 1950; movimentos } \\
\text { de vanguarda no Brasil e no mundo; aspectos da } \\
\text { biografia de Athos; processo formativo e } \\
\text { parcerias; modus operandi; classificação das } \\
\text { obras de Athos (arte ou ornamento); discussão } \\
\text { conceitual sobre cópia, citação e paródia. }\end{array}$ \\
\hline $\begin{array}{l}\text { A integração da Arte e } \\
\text { da Arquitetura em } \\
\text { Brasília: Lucio Costa } \\
\text { e Athos Bulcão }\end{array}$ & $\begin{array}{l}\text { Dissertação de } \\
\text { Mestrado }\end{array}$ & $\begin{array}{l}\text { Camila Christiana } \\
\text { de Aragão Tavares } \\
\text { (2016) }\end{array}$ & $\begin{array}{l}\text { A integração das artes na arquitetura; construção } \\
\text { de Braślia; Plano Piloto; movimentos de } \\
\text { vanguarda no Brasil e no mundo; Lucio Costa; } \\
\text { contextualização do cenário artístico na década } \\
\text { de 1950; aspectos da biografia de Athos; } \\
\text { processo formativo; parcerias de Athos com } \\
\text { arquitetos. }\end{array}$ \\
\hline $\begin{array}{l}\text { Ararquiazulathos: } \\
\text { Relações Estéticas } \\
\text { entre os Azulejos de } \\
\text { Athos Bulcão e o } \\
\text { Plano Piloto de } \\
\text { Brasília }\end{array}$ & $\begin{array}{l}\text { Dissertação de } \\
\text { Mestrado }\end{array}$ & $\begin{array}{l}\text { Camila Xavier da } \\
\text { Cunha (2016) }\end{array}$ & $\begin{array}{l}\text { A integração das artes na arquitetura; } \\
\text { movimentos de vanguarda no Brasil e no mundo; } \\
\text { construção de Brasília; Plano Piloto; história do } \\
\text { azulejo; aspectos da biografia de Athos; processo } \\
\text { formativo; parcerias de Athos com arquitetos; } \\
\text { azulejaria em Athos; modus operandi. }\end{array}$ \\
\hline $\begin{array}{lr}\text { A relação } & \text { arte- } \\
\text { arquitetura } & \text { no } \\
\text { trabalho de Athos } \\
\text { Bulcão para o Teatro } \\
\text { Nacional de Brasília: } \\
\text { concepções } \\
\text { materializações } \\
(1958-1981)\end{array}$ & $\begin{array}{l}\text { Dissertação de } \\
\text { Mestrado }\end{array}$ & $\begin{array}{l}\text { Luciana Fonseca de } \\
\text { Melo Adam (2018) }\end{array}$ & $\begin{array}{l}\text { Aspectos da biografia de Athos; processo } \\
\text { formativo; parcerias de Athos com arquitetos; } \\
\text { modus operandi; contextualização do cenário } \\
\text { artístico nas décadas de } 1940 \text { e } 1950 \text {; conceito de } \\
\text { troc. }\end{array}$ \\
\hline
\end{tabular}

Fonte: Autoras (2020)

\section{Análises}

A partir das leituras, sínteses e sistematizações realizadas, a primeira constatação foi que a maior parte das publicações sobre a produção artística de Athos Bulcão considera a relação de síntese ou integração entre as artes plásticas e a arquitetura. Dentro dessa abordagem, são discutidos também: sua produção azulejar no Brasil e no mundo; o caráter público de grande parte de sua obra; a modularidade e o processo criativo do artista; a possibilidade de interferência dos executores em 
alguns dos seus painéis; sua relação com Brasília; a Rede Sarah; o reflexo do cenário artístico nacional e mundial na criação do artista; os materiais e as tecnologias empregadas em suas obras; e as diferentes linguagens utilizadas. Nesse contexto, destacam-se, por suas abordagens, as dissertações e artigos de Adam (2018), Costa (2017), Cunha (2016), Leão (2012), Tavares (2016), Oliveira (2012a; $2012 \mathrm{~b} ; 2013)^{10}$ e Wanderley (2006), que trazem contribuições importantes para as discussões propostas no presente artigo.

Cunha (2016), Tavares (2016) e Wanderley (2006) fazem levantamentos sobre o artista, a partir da azulejaria, e tentam situar sua obra no cenário brasileiro e, ao mesmo tempo, estabelecer uma reflexão sobre a presença destas em espaços diversos. Wanderley (2006), mais precisamente, aborda a história do azulejo no Brasil, destacando a influência do Modernismo na produção de Athos Bulcão, assim como seu legado para outros artistas. Cunha (2016) discute o processo criativo do referido artista, também pautando sua investigação na produção azulejar, buscando compreender a intencionalidade de suas propostas. Apesar de também abordar a produção azulejar, Tavares (2016) estuda as percepções do conceito de integração pretendido por Lucio Costa (1902 - 1998) e Athos Bulcão para a cidade de Brasília, ambos intermediados por Oscar Niemeyer (1907 - 2012). Seu estudo se diferencia pela análise do caráter de integração no projeto da Igreja de Nossa Senhora de Fátima em Brasília, DF.

Nas duas dissertações, uma de mestrado profissional e outra de mestrado acadêmico, Oliveira (2012a; 2013) faz uma análise a partir do inventário da obra de Athos, empreendido pelo IPHAN, seguindo o viés da preservação do patrimônio e suas estratégias. Tais trabalhos proporcionam um panorama das obras integradas à arquitetura, ao mesmo tempo em que oferecem dados sobre a biografia do artista. No artigo apresentado em evento, Oliveira (2012b) coloca sua visão mais crítica acerca do caráter de integração na obra de Athos, questionando se tal integração ocorre de maneira efetiva em todas as suas colaborações com a arquitetura.

Um aspecto que interconecta uma série de estudos levantados, se não todos, são os conceitos relativos à "integração" e "síntese das artes". Porém, mesmo sendo um tema recorrente quando se fala da vida e da produção artística de Athos Bulcão, muitas vezes as discussões apresentadas se limitam a abordar as questões históricas, movimentos de vanguarda e suas características, focalizando apenas na perspectiva da arquitetura: como a postura dos arquitetos e suas definições de integração e síntese das artes. Pouco se fala sobre o discurso do artista ou do seu papel nesse processo.

Os referidos temas são abordados mais profundamente nos trabalhos de Adam (2018), Cunha (2016), Leão (2012), Oliveira (2013) e Tavares (2016), que trazem as discussões mais abrangentes sobre o tema. Oliveira (2012a; 2013), Tavares (2016) e Adam (2018), por exemplo, sugerem que o sentido de integração não ocorre em todas as obras de Athos, ao contrário do que é dito em muitos estudos sobre Athos Bulcão. Oliveira (2013) e Tavares (2016) afirmam que não houve a integração na obra de Athos realizada em parceria com o arquiteto Oscar Niemeyer, pois o arquiteto convidava o artista para colaborar após a concepção da edificação e não durante seu processo de criação. Nesse caso, as obras eram inseridas a posteriori na edificação, como apontado por Oliveira (2013).

Adam (2018) também questiona o conceito de "integração" na produção de Athos Bulcão e direciona sua análise para o Teatro Nacional de Brasília, projetado em parceria com o arquiteto Oscar Niemeyer. Contudo, diferente dos demais estudiosos, a autora aponta as estratégias do artista para a integração, reforçando a necessidade de uma revisão conceitual da produção artística desenvolvida no Modernismo brasileiro, já que o discurso desse movimento artístico no Brasil tem mantido, em um mesmo grupo, obras que foram realizadas para ocupar um espaço predeterminado na arquitetura e obras que foram feitas de modo independente e inseridas posteriormente, cabendo uma análise

\footnotetext{
${ }^{10}$ A recorrência de uma mesma autora com três diferentes trabalhos, Oliveira $(2012 \mathrm{a} ; 2012 \mathrm{~b}$; 2013) se dá por entender que cada um dos trabalhos possui diferentes contribuições sobre a temática abordada. O mesmo ocorre com Duarte (2008a; 2009).
} 
individual de cada uma dessas modalidades. Assim, Adam (2018) opta por uma análise no discurso dos envolvidos (no caso, o artista e o arquiteto), a fim de elaborar suas considerações. Interessa destacar ainda que a referida autora aborda a atuação acadêmica de Athos Bulcão durante seu período enquanto docente na UNB, as questões técnicas e materiais na expressão plástica do artista.

Por outro lado, Cunha (2016) sugere que o conceito de "integração" do Plano Piloto de Brasília só alcança sua realização plena através da parceria de Athos Bulcão com o arquiteto João Filgueiras Lima (1932-2014), o Lelé (apelido dado ao arquiteto na infância que o acompanhou em sua vida profissional). A autora apresenta as parcerias estabelecidas entre o artista e outros arquitetos, ponderando sobre as diferentes formas de colaboração. De modo semelhante, Telles (1997), Lago (2009), Leão (2012), Duarte (2008a; 2009), Duarte (2008b), Oliveira (2013), Tavares (2016) e Porto (2009a; 2009b) propõem que é com Lelé que a obra de Athos alcançou maior simbiose, entretanto, esses estudos não se aprofundam nos fatores que levaram a esse resultado diferenciado entre as colaborações. O que aponta para outra percepção que transpassa por quase todos os trabalhos é a comum consideração do caráter epidérmico da ideia de integração, como mero agente agregado fisicamente na arquitetura, desconsiderando a elaboração conceitual da obra de arte/arquitetura como parte do processo de integração.

Ainda sobre os conceitos de integração e síntese das artes e sua abrangência, Silva, Oliveira e Naslavsky (2016) colocam em destaque a autonomia de ambas as expressões (a obra de arte e a arquitetura) e citam a colaboração entre Athos Bulcão e o arquiteto Armando de Holanda Cavalcanti no projeto do Parque Histórico Nacional dos Guararapes (PHNG) (1975). Apesar de citar outras experiências, que culminaram na relação entre arte e arquitetura numa mesma edificação, seu discurso também colabora com o entendimento da arquitetura como protagonista no movimento de integração. Ainda no referido estudo, pouco se discute acerca das etapas da colaboração entre artista e arquiteto no PHNG, não sendo este um dos seus pontos focais.

Outra característica percebida em alguns trabalhos é o aparente apagamento/invisibilidade das obras de Athos Bulcão diante da arquitetura, fenômeno citado por Panitz (2018), Farias (2009) e Wanderley (2006), que apontam as técnicas utilizadas pelo artista (como azulejaria e murais), sua postura discreta (preferindo o anonimato) e sua relação com o meio urbano (obras ligadas fisicamente a edificações), como as possíveis responsáveis por tal diluição, já que a trajetória do artista foi consagrada especialmente a produção de obras voltadas para o público, não aquele que frequenta museus e galerias, mas sim os que provavelmente nunca teriam acesso à arte e não estão familiarizados com esta. Ele estava mais interessado no público que cruza com sua obra por acidente.

Tal percepção, sobre a preferência do artista e sua intencionalidade é confirmada através dos levantamentos feitos nas entrevistas e depoimentos cedidos pelo artista ao Programa de História Oral do Arquivo Público do Distrito Federal (BULCÃO, 1988) e a Moretzsohn (2009), onde fala de sua personalidade tímida, sua preferência por trabalhar para o grande público, e seu desejo pelo não reconhecimento, contido, sobretudo, no ato de não assinar a maior parte de suas obras em espaços de uso coletivo.

Observa-se que, em certa medida, essa percepção de apagamento também decorre do uso do termo "integração das artes”, que acaba por colocar essa produção num espaço de indefinição. Não sendo visto claramente como artes plásticas e, muitas vezes, confundindo-a com a estrutura arquitetônica. Mesmo identificando pesquisas que diferenciam as nuances sobre a produção artística de Athos, elas não abordam diretamente a questão da invisibilidade da obra de arte frente à sua diluição por meio da arquitetura e da cidade, o que se observa como resultado do movimento de integração das artes no Modernismo brasileiro.

Ainda nesse sentido, salta aos olhos a baixa ocorrência aprofundados sobre o caráter artístico da produção de Athos. No que diz respeito a essa escassez, Farias (2009) discorre sobre a dificuldade de encaixar tal produção em uma categoria de linguagem que a defina precisamente, o que colabora para 
que muitos historiadores a aproximem das artes aplicadas, da cenografia ou da produção arquitetônica modernista. Para Adam (2018), foi a trajetória do artista e sua escolha por um distanciamento dos temas abordados em seu tempo (no caso, questões sociais) que contribuíram para o atraso no interesse acadêmico por sua produção, pois, "[...] seu trabalho não ressoava no meio brasileiro, uma vez que seus temas picturais passavam ao largo das problematizações referentes à caracterização do 'homem brasileiro' ou das 'lutas de classe"' (ADAM, 2018, p.56). Assim, não houve interesse por parte dos historiadores pela produção de Athos até o final do século XX. Anterior a 1990, só havia depoimentos, catálogos e menções sobre o artista em um Dicionário Brasileiro de Artistas Plásticos (ADAM, 2018). Finalmente, para Farias (2009) o desconhecimento de Athos, dentre outras coisas, é consequência do ensino da história da arte que costuma favorecer alguns artistas em detrimento de outros, mantendo invisíveis seus importantes feitos.

Isso acarreta na escassez de dados sistematizados sobre a poética e o processo criativo do artista, deixando algumas lacunas a serem preenchidas, já que não foram localizados estudos que abordem profundamente sua concepção artística. Dentre os trabalhos pesquisados, apenas Adam (2018), Oliveira (2013) e Wanderley (2006) dão atenção a esses itens. Adam (2018) aponta as diretrizes do artista, dedicando um capítulo de sua dissertação a essa temática. Oliveira (2013), por sua vez, discute as soluções formais em duas obras específicas. Já Wanderley (2006) se propõe a falar da composição, processo criativo, temas e cores, mas sem ir além da azulejaria. Os demais trabalhos vistos, colocam informações e análises sobre o processo criativo de Athos, mas o fazem de maneira indireta; as análises mais aprofundadas são elaboradas em textos críticos ou curatoriais, tal como Duarte (2008b), Herkenhoff (1987), Costa (2017) e Panitz (2018). Destaca-se essa carência nas pesquisas por entender a compreensão da poética e do modus operandi do artista como requisito fundamental para discussão sobre suas obras.

Percebe-se que em sentido geral, poucos trabalhos estabelecem relação entre as obras de Athos (associando suas diversas técnicas e linguagens), no sentido de identificar características que se repetem ou que interferem em sua criação. Cunha (2016), Duarte (2008a; 2009), Oliveira (2012a) e Tavares (2016) propõem a análise sobre as características formais do azulejo na produção do artista, mas não elaboram claramente uma relação entre as técnicas ou as temáticas. Duarte (2008a; 2009) e Oliveira (2012a) chegam a sugerir um paralelo entre algumas obras, analisando quanto o processo de criação de uma pode ter interferido na outra. Apenas Leão (2012) faz uma proposição de separação de períodos na produção de Athos e qualifica algumas das suas realizações enquanto obras seminais e/ou obras de inflexão.

Nota-se também que nem todos os trabalhos se propuseram a observar o contexto histórico e a sua interferência na obra de Athos, bem como as produções contemporâneas ao artista, propondo associações, oposições ou similaridades entre os exemplares, mesmo sendo um aspecto extremamente relevante na pesquisa sobre artes. Dos que teceram alguma correlação dessa natureza, evidenciamse Adam (2018), Cardoso (2012), Cunha (2016), Lago (2009), Madeira (2002), Oliveira (2012a; 2012b) e Tavares (2016).

Por possuir uma abordagem histórica, Adam (2018) coloca o contexto tecnológico e suas influências nas soluções adotadas pelo artista. Também aponta as variações que ocorrem em cada parceria com arquitetos. Oliveira (2012a) e Cunha (2016) associam o trabalho de Athos com outros artistas, como Lygia Clark (1920-1988) e Hélio Oiticica (1937-1980), sempre mantendo o cuidado de demarcar os limites e as diferenças entre suas produções e finalidades. Madeira (2002) aproxima Athos Bulcão e Rubem Valentim (1922-1991), discutindo as diferentes aceitações de suas produções, além dos possíveis motivos que levaram um artista a ser mais bem aceito do que o outro.

Cardoso (2012) e Tavares (2016) abordam as similaridades entre as técnicas e soluções de integração em Athos Bulcão e Candido Portinari (1903-1962), destacando a azulejaria e a relação com a arquitetura modernista. Contudo, Cardoso (2012) enfatiza o aspecto ornamental nas duas produções azulejares e as coloca como complemento da arquitetura. Lago (2009), por sua vez, relaciona as obras 
de Athos Bulcão a outras obras ligadas à arquitetura e o Instituto do Patrimônio Histórico e Artístico Nacional (IPHAN) em 2009, na ocasião da elaboração do Inventário Nacional de Bens Móveis e Integrados $(\mathrm{INBMI})^{11}$ produzidos pelo artista para Brasília, elabora uma relevante associação entre as obras de Athos e seus contemporâneos. Tal análise inclui as características técnicas e estilísticas, estabelecendo similaridades entre suas obras e as de outros artistas, além de aproximações com movimentos artísticos.

Outra constatação foi a ausência de análises mais aprofundadas acerca da parceria de Athos e Lelé para a elaboração da Rede Sarah. Em sentido geral, são descritas apenas algumas das características dos objetos de arte presentes no Sarah, como seu material e técnica, ou, em outros casos, discute-se a inserção de cores em Estabelecimento de Atenção à Saúde. Pouco se fala do modo como a obra foi concebida para os espaços ou como se deu a parceria entre o artista e o arquiteto. Telles (1997), Lago (2009), Leão (2012), Duarte (2008a; 2009), Duarte (2008b), Oliveira (2013), Tavares (2016) e Porto (2009a; 2009b) mencionam a singularidade das propostas de Athos em colaboração com Lelé, contudo, não se aprofundam sobre a parceria e a forma como se deu a colaboração no seu processo de criação. Entretanto, o fato de sublinharem essa parceria entre as demais, denota que há algum elemento distintivo nesse encontro.

\section{Considerações Finais}

Com o intuito de refletir sobre o estado da arte das pesquisas acerca de Athos Bulcão, o levantamento proporcionou, inicialmente, uma maior aproximação com o artista, sua obra e seu modus operandi, dando dimensão da amplitude do seu trabalho e a abrangência de sua atuação, possibilitando uma visão geral da sua trajetória. Além disso, a reunião de dados contidos nas pesquisas forneceu um panorama do contexto e do processo formativo do artista, assim, foi possível conhecer suas referências e seus contemporâneos, bem como perceber como cada uma das atividades desempenhadas por ele colaboraram na construção de uma obra tão plural. Os levantamentos também revelaram uma enorme variedade de obras - algumas ainda pouco exploradas e documentadas - que, sem dúvida, possibilitariam um número quase infinito de investigações, que poderiam contemplar os processos artísticos, o modus operandi e outros aspectos da vida e produção (em constante catalogação, revisão e ampliação pela Fundathos) de Athos.

Através da ponderação de todas essas informações, percebeu-se a necessidade de olhar a integralidade do artista, a fim de compreendê-lo, o que direcionou a pesquisa de doutorado, do qual deriva este artigo. Para tanto, num segundo momento, os dados colhidos sobre o artista durante a Revisão Integrativa foram sistematizados e relacionados entre si. Desejando a visualização de todas as informações simultaneamente, buscou-se um modo de representação gráfica que permitisse considerar as obras e suas inter-relações, conexões, contextos e outros fatores externos ao artista. Assim, optou-se pela elaboração de um rizoma, baseado no entendimento de Deleuze e Guattari (1995). O rizoma que representa as principais obras da produção de Athos, foi a maneira de decompor sua obra em partes para estudar cada um de seus elementos, suas relações e contextos, evidenciando as inter-relações que se estabelecem. Esse sistema é relevante por permitir que sejam traçadas conexões entre obras de técnicas variadas ou realizadas em períodos diferentes, já que, em geral, os sistemas de inventário de coleções artísticas agrupam as obras por técnica ou período, dificultando o estabelecimento de tais relações.

A Revisão Integrativa possibilitou perceber o estado da arte das investigações sobre Athos e suas criações, ressaltando as lacunas, dentre estas, a baixa quantidade de estudos que contemplem as outras

\footnotetext{
${ }^{11}$ Em 2009, posterior a morte do artista Athos Bulcão, o Instituto do Patrimônio Histórico e Artístico - Distrito Federal (IPHAN-DF) e a Fundathos desenvolveram um Inventário Nacional dos Bens Móveis e Integrados (INBMI) do conjunto de obras do artista em Brasília, abrangendo o período de 1957 a 2007, contendo 261 obras. Em 2018, como parte da comemoração do centenário de nascimento do artista, o INBMI foi revisado e ampliado.
} 
formas de manifestação do artista, principalmente aquelas da sua primeira fase, relacionadas com as expressões gráficas (desenho, gravuras, serigrafia e ilustrações), assim como a pintura e a escultura. Dentre suas expressões que não são ligadas à arquitetura, apenas as fotomontagens possuem estudos aprofundados, mas não em quantidade tão significativa quanto os trabalhos relacionados aos azulejos. Os levantamentos também possibilitaram uma reflexão mais ampla sobre o modus operandi do artista, concluindo que este se pautava, resumidamente, em três pilares principais: a exploração de possibilidades, a colaboração e o ambiente.

Por fim, nota-se que, apesar da vasta produção do artista e da quantidade de estudos sobre sua obra, ela só é mais reconhecida por pesquisadores, mesmo povoando o inconsciente coletivo do Brasil e formando parte dos signos visuais de Brasília. Assim, tal como a obra de muitos outros artistas brasileiros, as obras de Athos Bulcão ainda precisam ser mais divulgadas e igualmente preservadas.

\section{Referências}

ADAM, Luciana Fonseca de Melo. A relação arte - arquitetura no trabalho de Athos Bulcão para o Teatro Nacional de Brasília: concepções e materializações (1958-1981). 2018. 239 f. Dissertação (Mestrado) - Curso de História, Setor de Ciências Humanas, Universidade Federal do Paraná, Curitiba, 2018. Disponível em: <https://acervodigital.ufpr.br/handle/1884/55666>. Acesso em: 01 set. 2018.

BAXANDALL, Michael. Padrões de Intenção: a explicação histórica dos quadros. São Paulo: Companhia das Letras, 2006.

BULCÃO, Athos. Depoimento - Programa de História Oral. Brasília, Arquivo Público do Distrito Federal, 1988.

CARDOSO, Sandra Magda Mattei. Os azulejos de Portinari e Athos Bulcão como elementos ornamentais da arquitetura modernista no Brasil. Revista Thêma Et Scientia, Cascavel, v. 2, n. 2, p. 65-74, jun. 2012. Semestral. Edição Especial de Arquitetura e Design. Disponível em: $<$ http://www.themaetscientia.fag.edu.br/index.php/RTES/article/view/110>. Acesso em: 01 out. 2017.

COSTA, Marcus de Lontra. Sinfonias de modernidade. 1987. Texto publicado originalmente na Revista Módulo. Disponível em: <http://www.fundathos.org.br/artigos>. Acesso em: 05 set. 2017.

COSTA, Marcus de Lontra. Athos Bulcão: tradição e modernidade. Rio de Janeiro: ADUPLA, 2017. 64 p. Catálogo de Exposição realizada na Caixa Cultural de Salvador de 12 de julho a 20 de agosto de 2017.

CUNHA, Camila Xavier da. ARARQUIAZULATHOS: Relações Estéticas entre os Azulejos de Athos Bulcão e o Plano Piloto de Brasília. 2016. 188 f. Dissertação (Mestrado) - Mestrado em Artes, Programa de Pós-Graduação em Arquitetura, Universidade de Brasília, Brasília, 2016. Disponível em: < http://repositorio.unb.br/handle/10482/22842>. Acesso em: 23 out. 2017.

DELEUZE, Gilles; GUATTARI, Félix. Introdução: Rizoma. In: DELEUZE, Gilles; GUATTARI, Félix. Mil platôs: capitalismo e esquizofrenia, Volume 1. Rio de Janeiro: Editora 34, 1995. p. 10-36.

DUARTE, Bárbara. Integração das artes: os azulejos de Athos Bulcão. Visualidades, [s.1.], v. 6, n. 12, p. 49-59, abr. 2008a. Universidade Federal de Goiás. http://dx.doi.org/10.5216/vis.v6i1 ei2.18069. Disponível em: <https://www.revistas.ufg.br/VISUAL/article/view/18069>. Acesso em: 02 nov. 2017.

DUARTE, Bárbara Pinto. VENTANIA, DE ATHOS BULCÃO: ruptura e integração. 2009. 108 f. Dissertação (Mestrado) - Mestrado em Artes, Programa de Pós-Graduação em Artes, Universidade 
de Brasília-UnB,

Brasília,

2009.

Disponível

em:

http://www.repositorio.unb.br/handle/10482/3839>. Acesso em: 12 nov. 2017.

DUARTE, Paulo Sergio. Sentido e urbanidade. Brasília: Fundação Athos Bulcão, 2008b. Disponível em: $<$ http://www.fundathos.org.br/pdf/Sentido\%20e\%20urbanidade\%20\%20Paulo\%20S_rgio\%20Duarte\%20port.pdf >. Acesso em: 01 nov. 2017.

FARIAS, Agnaldo. A obra de Athos Bulcão, ponto alto da vertente construtiva. In: SEMINÁRIO DOCOMOMO BRASIL - Cidade Moderna e Contemporânea: Síntese e paradoxo das artes, 8., 2009, Rio de Janeiro. Anais... . Rio de Janeiro: Docomomo Brasil, 2009. p. 1-11. Disponível em: < http://docomomo.org.br/course/8-seminario-docomomo-brasil-rio-de-janeiro/>. Acesso em: 25 jan. 2018.

FREITAS, Ranielder Fábio de; CARVALHO, Cintya Oliveira de; MENESCAL, Richarley Envangelista. Design Emocional e o designer como interpretador de desejos e necessidades: Revisão de Literatura. Estudos em Design, v. 18, n. 1, p. 1-18, jan. 2010. Semestral. Disponível em: $<$ http://estudosemdesign.emnuvens.com.br/design/article/view/46>. Acesso em: 10 set. 2015.

FUNDATHOS (Brasil). Fundação Athos Bulcão. Athos Bulcão: O artista. 2014. Disponível em: $<$ https://fundathos.org.br/>. Acesso em: 03 fev. 2016.

HERKENHOFF, Paulo. Para ver melhor Athos Bulcão. 1987. Apresentação da exposição individual Pinturas, Máscaras e Objetos Espaço Capital, Brasília e Galeria Saramenha, Rio de Janeiro. Disponível em: <http://www.fundathos.org.br/artigos>. Acesso em: 10 nov. 2017.

IPHAN-DF, Instituto do Patrimônio Histórico e Artístico Nacional (Brasil). Superintendência do IPHAN no Distrito Federal. Sandra Bernardes Ribeiro; Thiago Pereira Perpétuo (coord.). Inventário da obra de Athos Bulcão em Brasília. Brasília: Iphan, 2018. 210 p. Disponível em: $<$ http://portal.iphan.gov.br/uploads/publicacao/athosbulcatilde_menor.pdf $>$. Acesso em: 08 jan. 2019.

LAGO, André Correa do. Athos Bulcão. In: CABRAL, Valéria Maria Lopes. (Org.). Athos Bulcão. 1 ed. Brasília: Fundação Athos Bulcão, 2009, v. 1, p. 27-29. Disponível em: $<$ http://www.fundathos.org.br/pdf/Athos\%20Bulc_o\%20-

\%20Andr_\%20Correa\%20do\%20Lago\%20port.pdf >. Acesso em: 01 nov. 2017.

LEÃO, Leandro. A diluição do plano bidimensional no espaço: análises e relações entre quatro obras seminais de integração arquitetônica de Athos Bulcão. In: VIII EHA - Encontro de História da Arte, 8., 2012, Campinas. Anais... . Campinas: Unicamp, 2013. p. 341 - 359. Disponível em: $<$ http://www.unicamp.br/chaa/eha/atasVIIIeha.html>. Acesso em: 03 jan. 2018.

LIMA, João Filgueiras. Athos Bulcão. In: CABRAL, Valéria Maria Lopes; MARTINS, Rosanalha; PANITZ, Marília. Azulejos em Brasília, azulejos em Lisboa: Athos Bulcão e a tradição da azulejaria barroca. Brasília: Fundação Athos Bulcão, 2013. p. 57-59. Disponível em: $<$ http://www.fundathos.org.br/arquivos/Catálogo Athosmiolo.pdf>. Acesso em: 20 dez. 2017.

MADEIRA, Angélica. A Itinerância dos artistas: a construção do campo das artes visuais em Brasília (1958-1967). Tempo Social: Revista Sociologia, São Paulo, v. 14, n. 2, p. 187-207, out. 2002. Disponível em: < http://www.periodicos.usp.br/ts/article/view/12389>. Acesso em: 09 nov. 2017.

MELO, Magda M.. Síntese das Artes na Arquitetura de Oscar Niemeyer. Semina: Ciências Sociais e Humanas. Londrina, v. 24, n. 00, p. 121-130, set. 2003. Disponível em: $<$ http://www.uel.br/revistas/uel/index.php/seminasoc/article/view/3841>. Acesso em: 03 fev. 2018.

MORETZSOHN, Carmem. Habitante do silêncio em Brasília: Entrevista concedida pelo artista ao Jornal de Brasília, publicada no dia 2 de julho de 1998. In: CABRAL, Valéria Maria Lopes. (Org.). Athos Bulcão. 1 ed. Brasília: Fundação Athos Bulcão, 2009, v. 1, p. 356-363. Disponível em: 
$<$ http://www.fundathos.org.br/pdf/Habitante do silencio em Brasília - Carmem Moretzsohn port.pdf $>$. Acesso em: 15 abr. 2017.

OLIVEIRA, Fabiana Carvalho de. Estratégias para a preservação do patrimônio cultural moderno: Athos Bulcão em Brasília (1957-2007). 2012a. 186 f. Dissertação (Mestrado) - Curso de Preservação do Patrimônio Cultural, Instituto do Patrimônio Histórico e Artístico Nacional, Rio de Janeiro, 2012. Disponível em: $<$ http://portal.iphan.gov.br/pagina/detalhes/450>. Acesso em: 20 fev. 2018.

OLIVEIRA, Fabiana Carvalho de. Os painéis de Athos Bulcão na arquitetura de Brasília: Uma tradução Candanga do Projeto Construtivo Brasileiro?. In: Associação Nacional de Pesquisadores em Artes Plásticas, 21., 2012b, Rio de Janeiro. Anais... . Rio de Janeiro: ANPAP, 2012. p. 1399-1411. Disponível em: $<\mathrm{http} / /$ www.anpap.org.br/anais/2012/pdf/simposio8/fabiana_carvalho.pdf $>$. Acesso em: 10 nov. 2017.

OLIVEIRA, Fabiana Carvalho de. Ressignificações das obras de Athos Bulcão nos espaços de Brasília: Entre a obra de arte e o ornamento. 2013. 176 f. Dissertação (Mestrado) - Curso de Artes, Programa de Pós-Graduação em Artes, Universidade de Brasília-UNB, Brasília, 2013. Disponível em: $<$ http://repositorio.unb.br/handle/10482/14890>. Acesso em: 10 mai. 2017.

PANITZ, Marilia. O imaginário segundo Athos Bulcão. In: FUNDATOS (Brasil). Fundação Athos Bulcão. 100 anos de Athos Bulcão. Brasília: 4 Art Produção Cultural, 2018. p. 14-23.

PAREYSON, Luigi. Formação da obra de arte. In: PAREYSON, Luigi. Estética: teoria da formatividade. Petrópolis: Vozes, 1993. p. 59-92.

PORTO, Cláudia Estrela. Quando arte e arquitetura se mesclam: A obra de Athos Bulcão e Lelé. In: SEMINÁRIO DOCOMOMO BRASIL - Cidade Moderna e Contemporânea: Síntese e paradoxo das artes, 8., 2009a, Rio de Janeiro. Anais... . Rio de Janeiro: Docomomo Brasil, 2009. p. 1-21. Disponível em: < http://docomomo.org.br/course/8-seminario-docomomo-brasil-rio-de-janeiro/>. Acesso em: 21 jan. 2018.

PORTO, Cláudia Estrela. Athos Bulcão: a linha tênue entre arte e arquitetura. In: CABRAL, Valéria Maria Lopes. (Org.). Athos Bulcão. 1 ed. Brasília: Fundação Athos Bulcão, 2009b, p. 34-49. Disponível em: $<$ http://www.fundathos.org.br/pdf/A\%20linha\%20tenue\%20entre\%20arte $\% 20 \mathrm{e} \% 20$ arquitetura $\% 20$ -\%20Claudia\%20Estrela\%20Porto\%20-\%20port.pdf>. Acesso em: 21 nov. 2017.

SANTOS, Emyle dos Santos. Artes em diálogo: a produção de Athos Bulcão para a Rede Sarah. 2020. 270 f. Tese (Doutorado) - Programa de Pós Graduação em Artes Visuais, Universidade Federal da Bahia, Salvador, 2020. Disponível em: < http://www.ppgav.eba.ufba.br/pt-br/teses-dissertacoes $>$. Acesso em: 03 fev. 2021.

SILVA, Clarissa Carvalho e; OLIVEIRA, Adriana Freire de; NASLAVSKY, Guilah. Entre o concreto e o abstrato: as obras de Armando de Holanda Cavalcanti com Athos Bulcão. In: SEMINÁRIO NACIONAL DO DOCOMOMO BRASIL, 11., 2016, Recife. Anais [...] . Recife: Docomomo_Br, 2016. p. 1-12. Disponível em: http://seminario2016.docomomo.org.br/\#about. Acesso em: 02 abr. 2017.

SOUZA, Marcela Tavares de; SILVA, Michelly Dias da; CARVALHO, Rachel de. Revisão integrativa: o que é e como fazer. Revista Einstein, São Paulo, v. 8, n. 1, p. 102-106, jan. 2010. Trimestral. Disponível em: $<$ http://apps.einstein.br/revista/arquivos/PDF/1134-Einsteinv8n1_p102$106 \_$port.pdf $>$. Acesso em: 26 fev. 2018.

TAVARES, Camila Christiana de Aragão. A integração da arte e da arquitetura em Brasília: Lucio Costa e Athos Bulcão. 2016. 101 f. Dissertação (Mestrado) - Curso de Artes, Instituto de Artes 
da Universidade de Brasília (UnB), Brasília, 2016. Disponível em: $<$ http://repositorio.unb.br/handle/10482/21206>. Acesso em: 12 nov. 2017.

TELLES, Claudio. Sintonia de Arte e Arquitetura. Jornal de Brasília. Brasília, p. 1-2. 1997. Disponível em: <: http://www.fundathos.org.br/artigos>. Acesso em: 01 jan. 2018.

WANDERLEY, Ingrid Moura. Azulejo na arquitetura brasileira: os painéis de Athos Bulcão. 2006. 162 f. Dissertação (Mestrado) - Curso de Arquitetura, Urbanismo e Tecnologia, Escola de Engenharia de São Carlos, Universidade de São Paulo, São Paulo, 2006. Disponível em: $<$ http://www.teses.usp.br/teses/disponiveis/18/18141/tde-10112006-142246/pt-br.php>. Acesso em: 16 mar. 2018. 